\title{
Sellar Mature Teratoma
}

National Cancer Institute

\section{Source}

National Cancer Institute. Sellar Mature Teratoma. NCI Thesaurus. Code C155808.

A mature teratoma that arises from or adjacent to the sellar region. 